\title{
Sintesis dan karakterisasi minyak kelapa sawit untuk agensia peminyakan pada penyamakan kulit
}

\section{Synthesis and characterization of fatliquor from palm oil for fatliquoring agent on leather tanning}

\author{
Emiliana Kasmudjiastuti*, Gresy Griyanitasari, Dona Rahmawati, Sugihartono \\ Balai Besar Kulit, Karet, dan Plastik, Jl. Sokonandi No. 9 Yogyakarta, 55166, Indonesia \\ *Penulis korespondensi. Telp.: +62274 512929, 563939, Faks.: +62274563655 \\ E-mail: emilbbkkp@yahoo.com
}

Diterima: 11 Mei 2018 Direvisi: 10 Juli 2018 Disetujui: 25 Juli 2018

\begin{abstract}
The function of oil in the process of fatliquoring is to keep the skin fibers remain separate during the drying process and to reduce the friction force in woven fibers, so the skin becomes flexible. The objective of the study was to synthesize palm oil into sulfuric oil through sulphate process and characterization of palm oil and sulfate oil resulting from sulphate process. The method included palm oil synthesis using $25 \% \mathrm{H}_{2} \mathrm{SO}_{4}$ for 3 hours, at temperature $<20^{\circ} \mathrm{C}$, with $300 \mathrm{rpm}$ of speed. The result of characterization of palm oil shows that Iodine number $49.95 \mathrm{mg} \mathrm{I} /$ oil; free fatty acids $0.05 \%$; $0.18 \%$ moisture content; peroxide number $16.23 \mathrm{mg} / \mathrm{kg}$; acid number 0.19 $\mathrm{mg} \mathrm{KOH/g.} \mathrm{Most} \mathrm{of} \mathrm{saturated} \mathrm{fatty} \mathrm{acids} \mathrm{are} \mathrm{methyl} \mathrm{palmitate} \mathrm{and} \mathrm{methyl} \mathrm{butyrate,} \mathrm{while} \mathrm{the} \mathrm{unsaturated} \mathrm{fatty}$ acids are cis-9-oleic methyl ester and methyl linoleate. The resulting sulfuric oil has a moisture content of $6.47 \%$; pH at 8; $81.28 \%$ oil content; total alkalinity of $0.25 \% ; 192.74 \%$ saponification number; $2.77 \%$ ash content and bound $\mathrm{SO}_{3}$ content of $7.68 \%$. The tensile strength and elongation of the leather was $286.50 \mathrm{~kg} / \mathrm{cm}^{2}$ and $63.33 \%$, respectively.
\end{abstract}

Keywords: palm oil, sulfuric acid, sulfonation, sulfuric oil, fatliquoring.

\begin{abstract}
ABSTRAK
Fungsi minyak pada proses peminyakan kulit untuk menjaga agar serat kulit tetap terpisah selama proses pengeringan dan untuk mengurangi gaya gesekan dalam tenunan serat, sehingga kulit menjadi fleksibel. Tujuan penelitian untuk mensintesis minyak kelapa sawit menjadi minyak sulfat melalui proses sulfatasi dan karakterisasi minyak kelapa sawit dan minyak sulfat yang dihasilkan dari proses sulfatasi. Metode yang dilakukan meliputi sintesis minyak kelapa sawit menggunakan $25 \% \mathrm{H}_{2} \mathrm{SO}_{4}$ selama $3 \mathrm{jam}$, suhu $<20^{\circ} \mathrm{C}$, kecepatan $300 \mathrm{rpm}$. Hasil karakterisasi minyak kelapa sawit menunjukkan angka Iodin 49,95 mg $\mathrm{I}_{2} /$ minyak; asam lemak bebas 0,05\%; kadar air 0,18\%; angka peroksida 16,23 mg/kg; angka asam 0,19 mg KOH/gr. Asam lemak jenuh yang dominan adalah metil palmitat dan metil butirat, sedangkan asam lemak tidak jenuh yang dominan cis-9-oleic methyl ester dan metil linoleat. Minyak sulfat yang dihasilkan mempunyai kadar air 6,47\%; pH 8; kadar minyak 81,28\%; total alkalinitas 0,25\%, angka penyabunan 192,74\%; kadar abu 2,77\% dan kadar $\mathrm{SO}_{3}$ terikat 7,68\%. Hasil uji kekuatan tarik kulit tersamak adalah $286,50 \mathrm{~kg} / \mathrm{cm}^{2}$ dan kemuluran $63,33 \%$.
\end{abstract}

Kata kunci: minyak kelapa sawit, asam sulfat, sulfonasi, minyak sulfat, peminyakan.

\section{PENDAHULUAN}

Minyak kelapa sawit merupakan senyawa yang tidak larut dalam air, mempunyai karakteristik yang spesifik dibandingkan minyak nabati lainnya dengan kandungan asam lemak tidak jenuh 50,2\% (Rofiqi et al., 2016). Minyak kelapa sawit banyak digunakan sebagai bahan dasar untuk industri kosmetik, farmasi, pangan dan industri lainnya (Wang et al., 2012). Minyak kelapa sawit yang dikonsumsi sebagai minyak goreng tersedia dengan berbagai merek maupun tidak bermerek dikenal dengan minyak curah. Minyak curah biasanya hanya dilakukan proses penyaringan satu kali sampai pada tahap olein 
dan masih mengandung soft stearin (minyak fraksi padat). Minyak kelapa sawit adalah lemak semi padat yang mempunyai komposisi tetap. Titik lebur minyak sawit tergantung pada kadar trigliseridanya. Minyak kelapa sawit terdiri dari berbagai trigliserida dengan rantai asam lemak yang berbeda-beda. Panjang rantai $14-20$ atom karbon (Rofiqi et al., 2016).

Minyak yang digunakan dalam proses peminyakan kulit adalah golongan trigliserida yang diperoleh dari tanaman, hewan, dan ikan (Sarkar, 1995). Secara kimia minyak nabati, minyak dari hewan dan minyak ikan mengandung trigliserida (Strijbos et al., 2012). Minyak kelapa sawit terdiri atas trigliserida yang merupakan ester dari gliserol dengan tiga molekul asam lemak (Kassahun, 2014). Menurut Megahed dan Nashy (2010), sifat fisis dan kimia dari minyak kelapa sawit antara lain angka penyabunan 199,2 mg KOH/g minyak; angka Iodin 49,10 $\mathrm{mg} \mathrm{I}_{2} / \mathrm{g}$ minyak, angka peroksida $1,3 \mathrm{~m} \mathrm{Eq} / \mathrm{kg}$, angka asam 0,2 mg KOH/g minyak.

Proses peminyakan merupakan salah satu tahapan penting dalam proses pembuatan kulit, yang membuat kulit liat, lunak, fleksibel, lemas sesuai peruntukannya dan mempunyai efek terhadap sifat fisis kulit (Tawfik et al., 2017). Fungsi minyak pada proses peminyakan kulit adalah untuk menjaga serat tetap terpisah selama pengeringan dan untuk mengurangi gaya gesekan dalam tenunan serat (Nyamunda et al., 2013). Agensia peminyakan yang dimasukkan ke dalam jaringan kulit adalah dalam bentuk emulsi, sehingga untuk aplikasinya pada kulit, minyak yang digunakan dapat disintesis melalui proses sulfatasi, sulfitasi, fosfatasi maupun sulfonasi (Wang et al., 2012). Untuk mengubah minyak menjadi teremulsi perlu penambahan bahan kimia tertentu yang disebut pengemulsi seperti natrium bisulfit atau asam sulfat. Pengemulsi berfungsi untuk menurunkan tegangan permukaan (surface tension) antara molekul minyak dengan air. Dengan turunnya tegangan permukaan antara minyak dan air akan menaikkan kecenderungan minyak dan air untuk tercampur membentuk emulsi yang stabil (Sarkar, 1995).

Minyak hasil sulfatasi atau sulfonasi banyak digunakan pada industri kulit karena dapat memberikan dispersi minyak yang baik dan tidak sensitif terhadap asam (Nadew, 2014; Kassahun, 2014). Minyak sulfat dibuat dengan mereaksikan minyak hewan atau nabati dengan asam sulfat atau gas $\mathrm{SO}_{3}$ dengan suhu rendah (Sarkar, 1995) untuk menghindari terjadinya reaksi eksotermis. Penambahan asam sulfat secara pelan-pelan dan suhu reaksi harus dikontrol $<28^{\circ} \mathrm{C}$. Setelah sulfatasi selesai minyak sulfat dicuci menggunakan larutan garam untuk menghilangkan kelebihan asam bebas, selanjutnya minyak sulfat dinetralisasi menggunakan $\mathrm{NaOH}$ (Covington, 2009).

Penelitian ini bertujuan untuk mensintesis minyak kelapa sawit menjadi minyak sulfat melalui proses sulfatasi dan mengkarakterisasi minyak kelapa sawit dan minyak sulfat yang dihasilkan dari proses sulfatasi. Dalam penelitian ini bahan baku yang digunakan dan cara sintesis minyak berbeda dengan penelitian yang telah ada. Bahan baku yang digunakan adalah minyak kelapa sawit tanpa kemasan (minyak kelapa sawit curah) dan cara sintetis dengan modifikasi cara sulfatasi menurut Nurbalia (2000) serta Papalos dan Ledgewood (1975).

\section{BAHAN DAN METODE Bahan Penelitian}

Bahan yang digunakan dalam penelitian ini adalah minyak kelapa sawit curah dari distributor minyak curah Yogyakarta dan minyak jarak dari merek paten dari Yogyakarta. Kedua minyak tersebut belum disulfatasi. Bahan lain yaitu minyak Garboil BS, $\mathrm{H}_{2} \mathrm{SO}_{4} 98 \%$ teknis, $\mathrm{NaCl} 10 \%$ teknis, $\mathrm{NaOH}$ teknis, es batu, ice gel, kulit domba wet blue, wetting agent, asam formiat, dyestuff, syntan, mimosa, dan anti jamur.

\section{Peralatan Penelitian}

Alat yang digunakan dalam penelitian ini meliputi timbangan, pipet tetes, piranti gelas seperti gelas beker, termometer, pengaduk kaca, gelas ukur, corong pemisah, over head stirrer merek IKA Germany, klem dan statif, waskom stainless steel, LED digital hotplate magnetic stirrer, drum eksperimen Otto Specht dan FT-IR Spektrofotometer Thermo Scientific Nicolet iS 10.

\section{Metode Penelitian \\ Sintesis minyak sulfat}

Seratus gram minyak kelapa sawit curah dalam gelas beker yang dimasukkan ke dalam mangkok stainless steel yang berisi es batu, diaduk dengan mixer dengan kecepatan tetap $300 \mathrm{rpm}$, ditambahkan sulfating agent $\left(\mathrm{H}_{2} \mathrm{SO}_{4}, 25 \%\right.$ dari berat minyak) perlahan-lahan, suhu dijaga tidak lebih dari $20^{\circ} \mathrm{C}$. Proses sulfatasi berjalan lambat 
selama 3 jam. Minyak sulfat dicuci dengan larutan garam jenuh $(10 \% \mathrm{NaCl})$ suhu $35^{\circ} \mathrm{C}$ sebanyak tiga kali. Kemudian minyak dipisahkan dengan air garam. Minyak sulfat dinetralkan dengan larutan $50 \% \mathrm{NaOH}$ sampai $\mathrm{pH} 6,5-7$. Metode sulfatasi ini merupakan modifikasi cara sulfatasi dari Nurbalia (2000) serta Papalos dan Ledgewood (1975).

\section{Karakterisasi minyak kelapa sawit (raw material) dan minyak sulfat}

Karakterisasi meliputi uji fisiko kimia minyak kelapa sawit tanpa kemasan (minyak curah) yaitu uji asam lemak bebas, kadar air, angka peroksida, angka asam, dan angka Iodin. Sedangkan uji kimia minyak sulfat meliputi uji kadar air, $\mathrm{pH}$, kadar minyak, total alkalinitas, kadar abu, kadar $\mathrm{SO}_{3}$ terikat, dan analisis FT-IR serta uji komposisi asam lemak pada kulit tersamak.

\section{Proses peminyakan}

Kulit wet blue dicuci dengan air selama 10 menit dan air dibuang. Kemudian kulit dinetralisasi menggunakan $1 \%$ natrium format, $2 \%$ Tanigan PAK dalam $150 \%$ air, drum diputar selama 20 menit. Kemudian ditambah 0,8\% soda kue, drum diputar selama 45 menit, kulit diuji menggunakan bromo cresol green ( $\mathrm{pH} 5-5,5)$. Selanjutnya kulit dicuci dan disamak ulang menggunakan 2\% Novaltan PF, 4\% Tanicor RS38, 3\% Mimosa dan $3 \%$ Tanicor TNB, drum diputar selama 45 menit. Lalu ditambah $2 \%$ cat dasar dan $6 \%$ minyak sulfat hasil penelitian selama 60 menit dan difiksasi menggunakan $1 \%$ asam formiat.

\section{Uji sifat fisis kulit tersamak}

Uji fisis kulit tersamak meliputi kekuatan tarik dan kemuluran.

\section{HASIL DAN PEMBAHASAN \\ Sintesis Minyak Sulfat}

Pada penelitian ini, untuk mendapatkan minyak sulfat, minyak kelapa sawit curah ditambahkan asam sulfat. Reaksi asam lemak tak jenuh dengan asam sulfat bersifat eksotermis, oleh karena itu penambahan asam sulfat harus sangat lambat menggunakan pengaduk yang konstan untuk menghindari kenaikan temperatur (Nadew, 2014) dan dikondisikan pada suhu rendah $<28^{\circ} \mathrm{C}$ (Covington, 2009).

Sulfatasi adalah proses perlakuan minyak dengan asam sulfat pekat untuk mendapatkan minyak yang teremulsi dalam air. Pada proses sulfatasi dapat terjadi dua reaksi yaitu reaksi sulfatasi dan reaksi sulfonasi sekaligus karena adanya gugus hidroksil dan ikatan rangkap. Bila minyak bereaksi dengan gugus hidroksil, terjadi reaksi sulfatasi, bila bereaksi dengan ikatan rangkap, maka terjadi reaksi sulfonasi (Nadew, 2014). Minyak kelapa sawit tidak mempunyai ikatan hidroksil, hanya mempunyai ikatan rangkap terdiri dari asam oleat $\mathrm{CH}_{3}\left(\mathrm{CH}_{2}\right)_{7} \mathrm{CH}=\mathrm{CH}\left(\mathrm{CH}_{2}\right)_{7} \mathrm{COOH}$ dan asam linoleat $\mathrm{CH}_{3}\left(\mathrm{CH}_{2}\right)_{4} \mathrm{CH}=\mathrm{CHCHCH}=\mathrm{CH}\left(\mathrm{CH}_{2}\right)_{7} \mathrm{C}$ $\mathrm{O}_{2} \mathrm{H}$. Oleh karena itu reaksi yang terjadi adalah reaksi sulfonasi. Minyak sulfat yang baik adalah minyak yang banyak mengandung ikatan rangkap. Dalam proses sulfonasi, asam sulfat masuk ke dalam ikatan rangkap seperti halnya reaksi adisi yang menyebabkan minyak menjadi polar. Gugus sulfonat akan berikatan dengan atom $\mathrm{C}$ asam lemak jenuh menggantikan atom $\mathrm{H}$ atau dapat disebut sebagai reaksi subtitusi. Setelah terbentuk minyak sulfat, maka dilakukan pencucian menggunakan larutan $\mathrm{NaCl}$ dengan tujuan untuk menghilangkan sisa asam. Selanjutnya minyak sulfat dinetralisasi menggunakan larutan jenuh $\mathrm{NaOH}$ (Covington, 2009).

\section{Sifat Fisis-kimia}

Sifat fisis-kimia minyak kelapa sawit curah seperti pada Tabel 1. Dari Tabel 1 dapat dilihat bahwa nilai asam lemak bebas, kadar air dan angka asam masih dalam batas persyaratan SNI 7709:2012 Minyak goreng sawit. Kadar peroksida minyak kelapa sawit tanpa kemasan 16,23 milieq./kg jauh lebih tinggi dari persyaratan (BSN, 2012). Angka Iodin mencerminkanketidakjenuhan asam lemak penyusun minyak dan lemak.

Tabel 1. Sifat fisis-kimia dari minyak kelapa sawit curah.

\begin{tabular}{lcc}
\hline \multicolumn{1}{c}{ Parameter uji } & Hasil uji & SNI 7709:2012 \\
\hline Asam lemak bebas, \% b/v & 0,05 & Maks. 0,30 \\
Kadar air dalam minyak, \% & 0,18 & Maks. 0,10 \\
Angka peroksida, mg/kg & 16,23 & Maks. 10 \\
Angka asam, mg KOH/g & 0,19 & Maks. 0,6 \\
Angka Iodin, mg I/g minyak & 49,95 & - \\
\hline
\end{tabular}


Angka Iodin yang tinggi menunjukkan tingginya ketidakjenuhan minyak. Nilai angka Iodin minyak sawit tanpa kemasan adalah 49,95 mg I/minyak tidak jauh berbeda dengan angka Iodin minyak kelapa sawit hasil penelitian Megahed dan Nashy (2010) yaitu $49,10 \mathrm{mg} \mathrm{I} /$ minyak.

\section{Spesifikasi Minyak Sulfat}

Rata-rata hasil uji minyak sulfat (kadar air, $\mathrm{pH}$, kadar minyak, total alkalinitas, angka penyabunan, kadar abu, kadar $\mathrm{SO}_{3}$ terikat) dengan waktu pengadukan 3 jam disajikan pada Tabel 2, dan sebagai kontrol digunakan minyak nabati yang dipakai di pasaran.

Dari Tabel 2 dapat dilihat bahwa hasil uji kadar air, $\mathrm{pH}$, kadar minyak, total alkalinitas, dan kadar abu termasuk kontrol, memenuhi persyaratan IS: 6357-1971. Uji kadar $\mathrm{SO}_{3}$ terikat dimaksudkan untuk mengetahui jumlah asam sulfat yang mengadisi ikatan rangkap setelah terjadinya reaksi sulfonasi. Semakin banyak kandungan $\mathrm{SO}_{3}$ yang terikat pada minyak sulfat, bila diaplikasikan pada kulit $\mathrm{SO}_{3}$ akan berikatan dengan $\mathrm{H}_{2} \mathrm{O}$ sehingga membentuk $\mathrm{H}_{2} \mathrm{SO}_{4}$ yang akan merusak kulit yang disamak. Bilangan penyabunan adalah jumlah miligram $\mathrm{KOH}$ yang diperlukan untuk menyabunkan satu gram minyak/ lemak. KOH yang ditambahkan pada minyak sulfat akan memutuskan ikatan yang terjadi antara asam sulfat dan minyak, selanjutnya $\mathrm{KOH}$ bereaksi dengan asam lemak dari minyak menggantikan posisi asam sulfat. Pada reaksi penyabunan terjadi reaksi gugus $\mathrm{SO}_{4} \mathrm{H}$ dari minyak sulfat dan reaksi terhadap gugus $\mathrm{COOH}$ dari asam lemak, sehingga bilangan penyabunan minyak sulfat $(192,74 \mathrm{mg}$ $\mathrm{KOH} / \mathrm{g}$ ) lebih besar dari minyak kelapa sawit (40,05 $\mathrm{mg} \mathrm{KOH} / \mathrm{g})$. Analisis angka penyabunan dimaksudkan untuk mengetahui jumlah gugus sulfat yang terikat pada minyak.

Tabel 2. Rata-rata hasil uji minyak sulfat.

\begin{tabular}{lccc}
\hline \multicolumn{1}{c}{ Parameter uji } & Konsentrasi $\mathrm{H}_{2} \mathrm{SO}_{4}$ & & \\
& $25 \%$ & Kontrol & Persyaratan IS: 6357-1971 \\
\hline Kadar air (\%) & 6,47 & 25,09 & Maks. 35,00 \\
pH & 8,00 & 5,46 & $6,5-8$ \\
Kadar minyak (\%) & 81,28 & 64,39 & Min. 60 \\
Total alkalinitas (\%) & 0,25 & 1,51 & Maks. 3 \\
Angka penyabunan (\%) & 192,74 & 86,09 & - \\
Kadar abu (\%) & 2,77 & 2,83 & Maks. 3 \\
Kadar $\mathrm{SO}_{3}$ terikat (\%) & 7,68 & 5,09 & - \\
\hline
\end{tabular}

Tabel 3. Komposisi asam lemak minyak kelapa sawit dan minyak sulfat.

\begin{tabular}{lcc}
\hline \multicolumn{1}{c}{ Nama asam lemak } & Minyak kelapa sawit (\%) & Minyak sulfat (\%) \\
\hline Methyl butyrate & 7,47 & - \\
Methyl decanoate & - & 0,15 \\
Methyl laurate & 1,02 & 1,11 \\
Methyl tetradecanoate & 1,05 & 1,96 \\
Methyl palmitate & 35,76 & 48,61 \\
Methyl Palmitoleate & 0,12 & - \\
Methyl Octadecanoate & 3,61 & 5,13 \\
Trans-9-elaidic acid methyl ester & - & 0,58 \\
Cis-9-Oleic methyl ester & 39,37 & 31,80 \\
Linolelaidic acid methyl ester & - & 5,37 \\
Methyl linoleate & 11,02 & - \\
Methyl arachidate & 0,26 & 0,27 \\
Methyl cis-5,8,11,14,17-Eicosapentanoate & - & 3,75 \\
Methyl docosanoate & - & 0,43 \\
Cis-13,16-Docosadienoic acid methyl ester & - & 0,22 \\
Methyl tricosanoate & - & 0,62 \\
Methyl cis -11-eicosenoate & 0,32 & - \\
\hline Total: & 100,00 & 100,00 \\
\hline
\end{tabular}




\section{Komposisi asam lemak}

Komposisi asam lemak minyak kelapa sawit dan minyak sulfat pada kulit disajikan pada Tabel 3. Dari Tabel 3 dapat dilihat bahwa asam lemak jenuh berupa metil butirat yang terdapat pada minyak kelapa sawit tidak dijumpai pada minyak sulfat. Hal ini diduga karena metil butirat telah hilang pada saat pencucian ataupun telah tersabunkan pada saat netralisasi menggunakan $\mathrm{NaOH}$. Sedangkan asam lemak jenuh berupa asam palmitat yang terdapat pada minyak kelapa sawit yang semula $35,76 \%$, setelah menjadi minyak sulfat yang diaplikasikan pada kulit jumlahnya bertambah menjadi 48,61\%. Metil oktadekanoat yang terdapat pada minyak kelapa sawit yang semula 3,61\% menjadi 5,13\%. Hal ini diduga masih adanya lemak natural yang terdapat pada kulit karena proses penghilangan lemak (degreasing) yang belum sempurna dan adanya minyak yang ditambahkan pada pembuatan kulit wet blue. Asam lemak tidak jenuh berupa cis-9oleic methyl ester yang terdapat pada minyak kelapa sawit 39,37\% setelah menjadi minyak sulfat yang diaplikasikan pada kulit jumlahnya berkurang menjadi $31,80 \%$. Demikian juga metil linoleat yang terdapat pada minyak kelapa sawit sejumlah $11,02 \%$ setelah menjadi asam sulfat yang diaplikasikan pada kulit menjadi tidak ada. Hal tersebut diduga karena sebagian cis-9-oleic methyl ester bereaksi dengan asam sulfat dan metil linoleat telah bereaksi semua dengan asam sulfat.
Sedangkan metil ester linolelaidic acid dan metil cis 5, 8, 11, 14, 17 eicosapentanoate tidak terdapat pada minyak kelapa sawit, setelah menjadi asam sulfat yang diaplikasikan pada kulit berturut-turut menjadi 5,37\% dan 3,75\%. Hal ini diduga masih adanya lemak alami yang terdapat pada kulit karena proses penghilangan lemak (degreasing) yang belum sempurna dan adanya minyak yang ditambahkan pada pembuatan kulit wet blue.

\section{Analisis FT-IR}

Analisis FT-IR minyak kelapa sawit dan minyak sulfat $\left(25 \% \mathrm{H}_{2} \mathrm{SO}_{4}-3\right.$ jam $)$ disajikan pada Gambar 1. Gambar 1 menggambarkan FTIR (absorbance) spektrum minyak kelapa sawit dan minyak sulfat hasil sulfatasi minyak kelapa sawit $\left(25 \% \mathrm{H}_{2} \mathrm{SO}_{4}-3 \mathrm{jam}\right)$ dari range 4000 sampai $1000 \mathrm{~cm}^{-1}$. Spektrum dari minyak kelapa sawit, menunjukkan puncak (peak) penyerapan dan penyempitan pada 3006,02 dan $721,35 \mathrm{~cm}^{-1}$ diberikan oleh asam lemak tak jenuh cis-9-oleic methyl ester (cis=CH). Penyerapan puncak yang kuat sekitar 2921,66 sampai $2852 \mathrm{~cm}^{-1}$ yaitu getaran peregangan asimetris $\mathrm{CH}_{3}$ dan $\mathrm{CH}_{2}$. Spektrum menunjukkan peregangan pita penyerapan pada 1743,25 dan $1464,30 \mathrm{~cm}^{-1}$ yang sesuai dengan ikatan konjugasi masing-masing (cis $\mathrm{C}=\mathrm{C}$ ) dan $\mathrm{C}-\mathrm{H}$.

Spektrum minyak sulfat, menunjukkan puncak (peak) penyerapan dan penyempitan pada 3401,16 dan $715,52 \mathrm{~cm}^{-1}$ diberikan oleh

Tabel 4. Data analisa kuantitatif spektrum FT-IR.

\begin{tabular}{lcr}
\hline \multicolumn{1}{c}{ Gugus fungsional } & Minyak kelapa sawit & \multicolumn{1}{c}{ Minyak sulfat } \\
\hline $\mathrm{Cis}=\mathrm{CH}$ & $(3006,02 \& 721,35) \mathrm{cm}^{-1}$ & $(3401,16 \& 715,52) \mathrm{cm}^{-1}$ \\
$\mathrm{CH}_{3}$ dan $\mathrm{CH}_{2}$ & $2921,66-2852 \mathrm{~cm}^{-1}$ & $2953,32-2850,71 \mathrm{~cm}^{-1}$ \\
$\mathrm{Cis} \mathrm{C}=\mathrm{C}$ dan $\mathrm{C}-\mathrm{H}$ & $(1743,25 \& 1464,30) \mathrm{cm}^{-1}$ & $1651,44 \& 1466,05 \mathrm{~cm}^{-1}$ \\
\hline
\end{tabular}

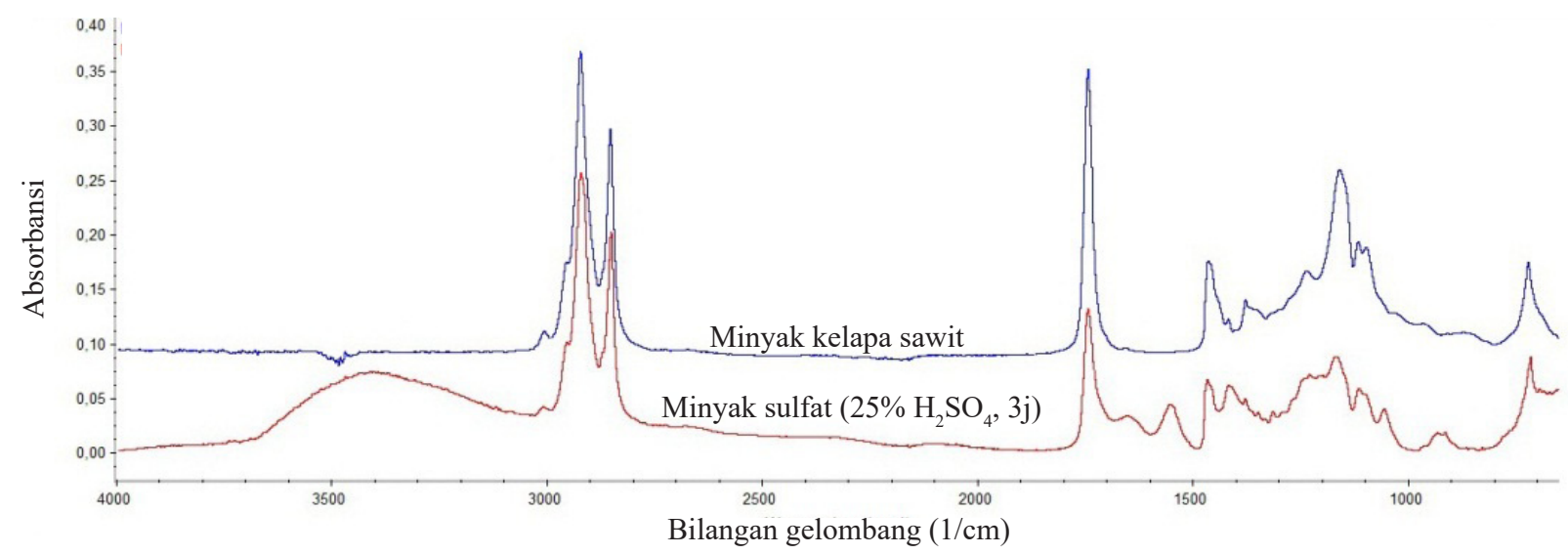

Gambar 1. FT-IR spektrum minyak kelapa sawit dan minyak sulfat. 
asam lemak tak jenuh cis-9-oleic methyl ester $(\mathrm{cis}=\mathrm{CH})$. Penyerapan puncak yang kuat sekitar 2953,18 sampai $2850,71 \mathrm{~cm}^{-1}$ yaitu getaran peregangan asimetris $\mathrm{CH}_{3}$ dan $\mathrm{CH}_{2}$. Spektrum menunjukkan peregangan pita penyerapan pada 1651,44 dan $1466,05 \mathrm{~cm}^{-1}$ yang sesuai dengan ikatan konjugasi masing-masing ( cis $\mathrm{C}=\mathrm{C}$ ) dan C-H. Data pada Tabel 4 menunjukkan adanya persamaan gugus-gugus fungsional pada minyak kelapa sawit dan minyak sulfat hasil sulfatasi minyak kelapa sawit $\left(25 \% \mathrm{H}_{2} \mathrm{SO}_{4}-3\right.$ jam $)$ seperti cis-9-oleic methyl ester $(\mathrm{cis}=\mathrm{CH}) ; \mathrm{CH}_{3}$ dan $\mathrm{CH}_{2}$; dan cis $\mathrm{C}=\mathrm{C}$ dan $\mathrm{C}-\mathrm{H}$.

\section{Kekuatan Tarik dan Kemuluran}

Kekuatan tarik dan kemuluran merupakan parameter uji untuk mengetahui kekuatan fisik kulit tersamak. Hasil uji kekuatan tarik kulit tersamak menggunakan minyak sulfat hasil penelitian adalah $286,50 \mathrm{~kg} / \mathrm{cm}^{2}$ di atas persyaratan SNI 0253:2009 Kulit bagian atas alas kaki-kulit kambing, yang mempersyaratkan minimal $160 \mathrm{~kg} / \mathrm{cm}^{2}$ dan kulit jadi menggunakan minyak sulfat paten (kontrol) adalah $226,46 \mathrm{~kg} /$ $\mathrm{cm}^{2}$. Untuk produk alas kaki, tidak diperlukan kemuluran yang tinggi. Hasil uji kemuluran kulit jadi menggunakan minyak sulfat hasil penelitian adalah 63\%, kontrol 70,28\%. SNI 0253:2009 mempersyaratkan kemuluran maksimum 55\%. Tingginya nilai kemuluran diduga karena penggunaan minyak $6 \%$ untuk produk sepatu terlalu banyak, sehingga menghasilkan nilai kemuluran yang tinggi.

\section{KESIMPULAN}

Dari hasil sintesis dan karakterisasi minyak kelapa sawit curah dapat disimpulkan bahwa minyak kelapa sawit curah dapat disintesis menggunakan $25 \% \mathrm{H}_{2} \mathrm{SO}_{4}$ dengan waktu sulfatasi 3 jam, kecepatan $300 \mathrm{rpm}$, dimana reaksi yang terjadi adalah reaksi sulfonasi. Karakterisasi minyak kelapa sawit adalah angka Iodin 49,95 mg $\mathrm{I}_{2}$ /minyak; asam lemak bebas $0,05 \%$; kadar air $0,18 \%$; angka peroksida $16,23 \mathrm{mg} / \mathrm{kg}$; angka asam $0,19 \mathrm{mg} \mathrm{KOH} / \mathrm{g}$; asam lemak jenuh yang dominan adalah metil palmitat dan metil butirat; asam lemak tidak jenuh yang dominan adalah cis-9-oleic methyl ester dan metil linoleat. Data spektrum FT-IR minyak sulfat menunjukkan gugus cis $=\mathrm{CH} ; \mathrm{CH}_{3}$ dan $\mathrm{CH}_{2}$ dan cis $\mathrm{C}=\mathrm{C}$ dan $\mathrm{C}-\mathrm{H}$ yang serupa dengan minyak kelapa sawit dan masih terdapat cis-9-oleic methyl ester.
Minyak sulfat yang dihasilkan dari sintesis minyak kelapa sawit dengan $25 \% \mathrm{H}_{2} \mathrm{SO}_{4}$ selama 3 jam, mempunyai kadar air 6,47\%; pH 8; kadar minyak $81,28 \%$; total alkalinitas $0,25 \%$, angka penyabunan $192,74 \%$; kadar abu 2,77\% dan kadar $\mathrm{SO}_{3}$ terikat $7,68 \%$. Minyak sulfat hasil penelitian dapat digunakan sebagai agensia fatliquoring pada proses penyamakan kulit dengan nilai kekuatan tarik pada kulit tersamak adalah $286,50 \mathrm{~kg} / \mathrm{cm}^{2}$ dan kemuluran $63,33 \%$.

\section{UCAPAN TERIMA KASIH}

Penelitian ini didanai oleh DIPA Balai Besar Kulit, Karet dan Plastik tahun anggaran 2017. Penulis mengucapkan terima kasih kepada seluruh anggota tim penelitian.

\section{DAFTAR PUSTAKA}

BSN (Badan Standardisasi Nasional). (2012). Standar Nasional Indonesia SNI 7709:2012: Minyak goreng sawit. Jakarta, Indonesia: BSN.

BIS (Bureau of Indian Standards). (1971). Indian Standards IS 6357-1971: Sulphated oil for leather fat liquoring. New Delhi, India: BIS.

Covington, A. D. (2009). Tanning chemistry: The science of leather. Cambridge, UK: The Royal Society of Chemistry.

Kassahun, W. (2014). Preparation of leather fatliquor cum filler from fleshing waste for retanning process in leather manufacture (Thesis). Addis Ababa University, Addis Ababa, Ethiopia.

Megahed, M. G., \& Nashy, E. H. A. (2010). Ester phosphate of discarded palm oil from potato chip factories as fat-liquoring agent. Journal of American Science, 6(12), 617-626. https://doi.org/10.7537/marsjas061210.70

Nadew, S. G. (2014). Fatliquor product development from Vernonia galamensis seed oil via modified sulphitation process (Thesis). Addis Ababa University, Addis Ababa, Ethiopia.

Nurbalia, E. (2000). Penerapan minyak sulfat dari bahan dasar minyak sawit pada kulit wetblue sapi untuk garmen ditinjau dari kekuatan tarik dan elongasinya. Yogyakarta, Indonesia: Akademi Teknologi Kulit.

Nyamunda, B. C., Moyo, M., \& Chigondo, F. (2013). Synthesis of fatliquor from waste bovine fat for use in small scale leather industry. Indian Journal of Chemical Technology, 20(2), 116-120.

Papalos, J. G., \& Ledgewood, N. J. (1975). US Patent No. 437,053. Washington, USA: U.S. Patent and Trademark Office.

Rofiqi, D. M., Maarif, M. S., \& Hermawan, A. (2016). Strategi percepatan pengembangan industri turunan minyak sawit mentah (MSM) di Indonesia. Jurnal Teknologi Industri Pertanian, 
26(3), 246-254.

Sarkar, K. T. (1995). Theory practice leather manufacture. Madras, India: The CLS Press.

Strijbos, L., Saumweber, R., Hess, M., Gabagnou, C., \& Fennen, J. (2012). High-fastness fatliquors from sustainable resources. World Leather, 20, 19-21.

Tawfik, H. M., Gasmelseed, G. A., \& Mohammed, F. E. F. (2017). Using characterization and synthesis of fatliquor from Sudanese castor oil. Indian Journal of Medical Research and Pharmaceutical
Sciences, 6(2), 11-16.

https://doi.org/10.5281/zenodo.266664

Wang, C., Li, T., \& Feng, S. (2012). Synthesis of fatliquor from palm oil and hydroxyl-terminated organosilicon. Asian Journal of Chemistry, 24(1), 63-67. 
